(C) Springer-Verlag 1993

\title{
Orthopédie-Traumatologie is two years old!
}

When two years ago we carried on the font our Review, we were grasped by quite an anguish: "what if the baby shouldn't grow up?". You who read us, you who from the four corners of Europe send us articles, be here thanked, you have contributed to help the child grow. Our review of which this is the 11 th issue exists and prospers.

Our first thanks go to Professor Philippe Vichard who entrusted us the heritage of "the Annals of the S.O.T. EST", which allowed us, adding to them the annual works of the GECO to make use of a pool of quality scientific rotation but which until now was only printed and not edited.

To our new readers, allow me to recall what the S.O.T.EST and the GECO are. Founded in 1973 at the initiative of Jean-Nicolas Muller, Ivan Kempf, Jacques Michon, Lucien Molé, Eugène Schvingt, Jean Sommelet et Philippe Vichard, the S.O.T.EST included at the start the three regions Alsace, Franche-Comté and Lorraine. Very quickly, these three regions were joined by Champagne-Ardennes then Burgundy and by about fifty orthopxdicians extra-regional and extra-national. Two scientific annual meetings until 1988 , only one since 1989 , in order to avoid dispersion, permit to the S.O.T.EST to bring together, between 90 and 130 of its 250 registered members, to propose at each meeting two Round Tables and to welcome about thirty particular communications.

The GECO was born in 1976 , as a platform of alpine annual meetings, thanks to an intelligent link between "Science and Industry" initiated by Fournitures Hospitalières. Four days of daily work from 8.00 a.m. to 10.30 a.m. and from 4.30 p.m. to 8.00 p.m., interrupted by skiing between 10.30 a.m. and 4.30 p.m. constitute the the basic program of the GECO, allying the saying "mens sana in corpore sano". During those days, too, there are two Round Tables and about fifteen conferences, gathered within Reports distributed to all participants. From 40 participants in 1976, the GECO gathered 160 surgeons at its XVII th congress in January 1993. It is to be hoped that the Law of January 27th, 1993 be amended to allow the survival of a group open to all participants and where all subjects have always been discussed, without any exclusive nor directive, the industrial sponsor lea- ving, of course, every scientific freedom to the group.

The junction S.O.T.EST - GECO thus made it possible to put in common their annual works in the form of free papers or monographs. This nevertheless would not have been sufficient to give our review a European radiance, radiance desired from the beginning by the editor Springer-Verlag France. The bilingual character, French and English imposed itself slowly, attracting AngloSaxon, Scandinavian or even Greek works, bringing more and more exterior articles to both founding societies. All the articles are analysed and criticized by a Reading Committee which I wish to thank here for the responsive and seriousness of its work.

In the building Europe, our young review wants to be one of the tools of communication between orthopædicians close to big national reviews, favoring the works of both founding groups but also those of European teams of all horizons.
Professor Kehr Editor in Chief 